بررسى خصوصيات سبز شدن جوانه و رشد كياهجه ارقام تجارى نيشكر ( Saccharum (officinarum در تاريخهاى مختلف كاشت وسن

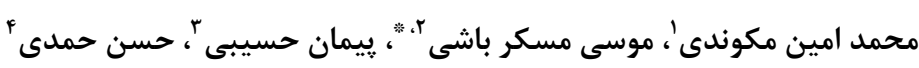

جكيده مبسوط مقدمه: تنظيم برنامههاى مديريتى عمليات زراعى در مزارع نيشكر مى بايست با شناخت دقيق و كافى از مراحل رشد، نمو و و

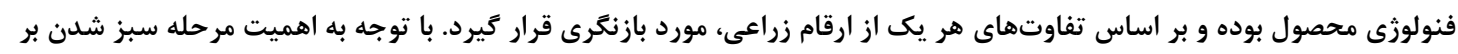

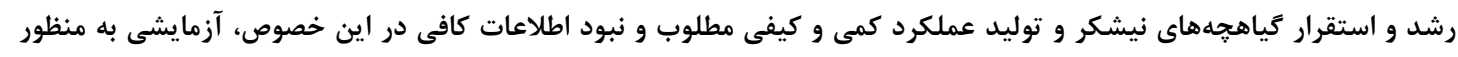

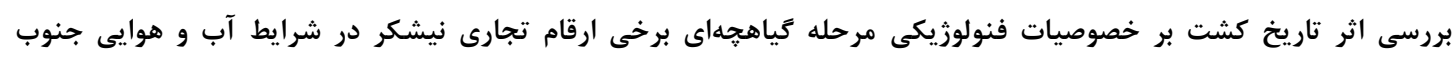
خوزستان در دو سال زراعى و

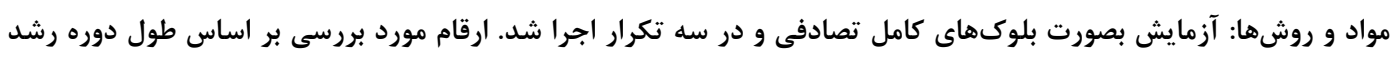

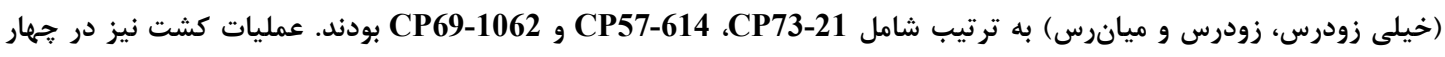

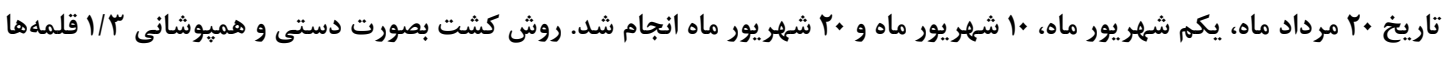

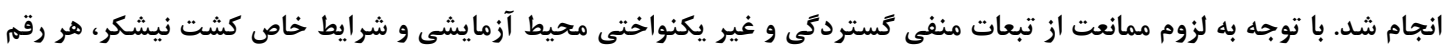

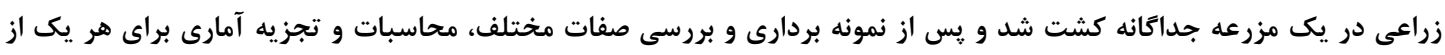
ارقام بصورت جداكانه انجام ترديد.

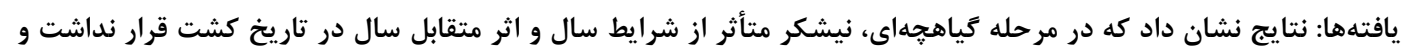

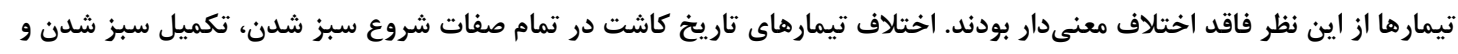

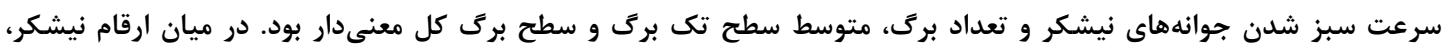
سريعترين شروع، تكميل و سرعت سبز شدن را رقم

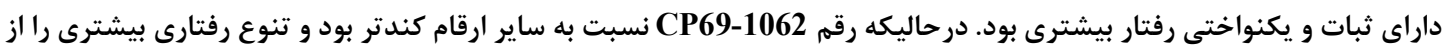
نظر سبز شدن جوانهها در تاريخهاى مختلف كشت نشان داد؛ اما رقم

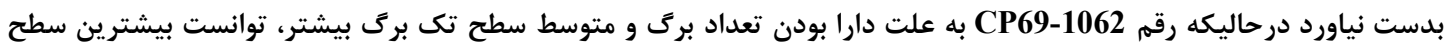

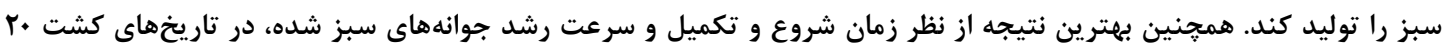

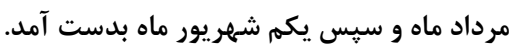

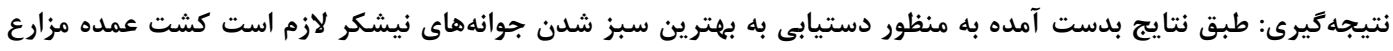

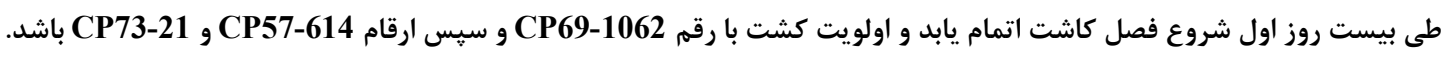

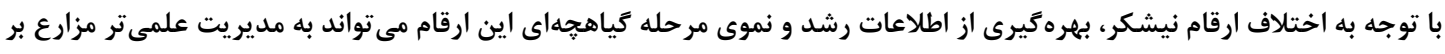

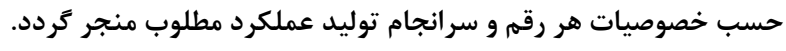

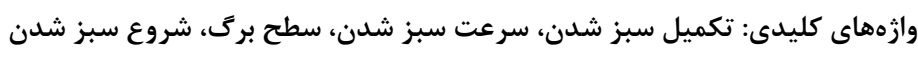
جنبههاى نوآورى:

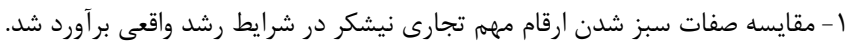

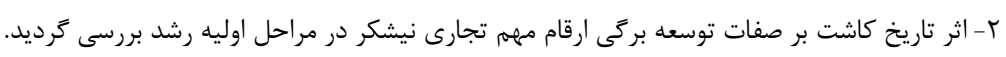

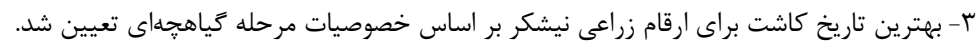

http://dorl.net/dor/20.1001.1.23831251.1398.6.2.8.0

http://dx.doi.org/10.29252/yujs.6.2.81

CrossMark

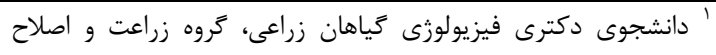

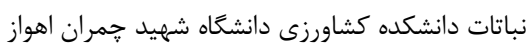

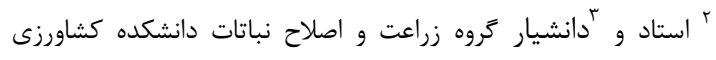

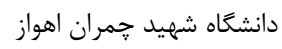
" محقق موسسه تحقيقات و آموزش نيشكران فران شركت توسعه نيشكر و صنايع جانبى مجن موسن 
ينجهزنى نيشكر برآورد كرد. همجنين دماى پإيه ظهور برك را | | ادرجه سلسيوس كزارش نمود كه توسط ساير

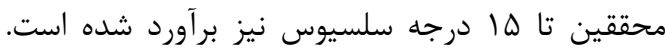

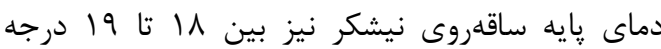
سلسيوس محاسبه و گزارش شده است (ليو و همكاران،

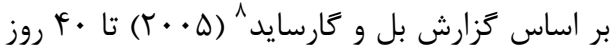
بعد از كاشت قلمههاى نيشكر، تنها ساقه اصلى رشد كرد آند و بعد از آن به سرعت تراكم ساقه افزايش يافت كه عمده لندان

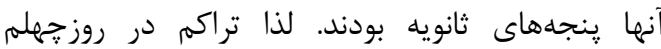
بلعنوان تراكم (تراكم ساقههاى رويش يافته از جوانههاى اصلى) جوانههاى اصلى مدنظر قرار كرفت. طبق نتايج كزارش شده از سوى برخى محققين، طيف تكميل

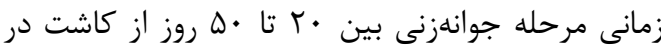

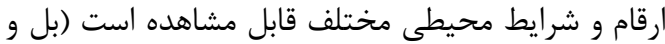

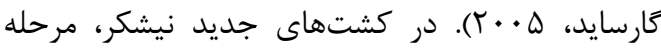
جوانهزنى طولانى بوده ولى مزارع بازرويى زودتر به زمان حداكثر ينجهزنى مىرسند، لذا در اين مزارع ينجهانئى

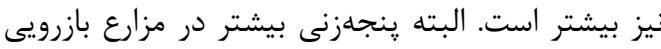

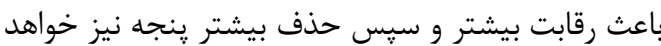
شد. به منظور مديريت بدون تنش مراحل نموى نيشكر،

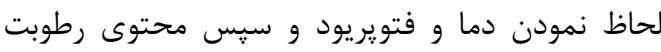
خاى، مواد غذايى و تشعشع خورشيدى از اهميت ويزهاى برخوردار است، زيرا فاصله زمانى دو مرحله رشدى متوالى در شرايط مطلوب رشدى و بدون تنش در در حالت بهينه بوده و سرعت نمو در حداكثر قرار دارئ دارد

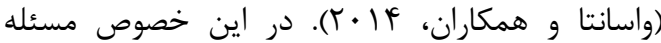

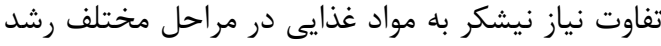

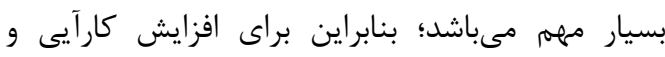
بهرهورى بهتر از نهادههاى مصرفى، مىبايست مصرف

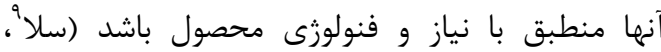

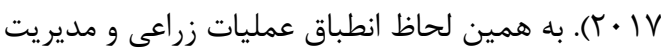
عملياتهاى كاشت و داشت مزرعه مىبايست با شناخت كافى از فنولوزى كياه زراعى صورت يذيرد. دو دسته از عوامل بر مدت زمان مراحل رشد و ونموى لنوى اثر دارند. عوامل داراى اثر كمّى بر مدت زمان زمان مراحل مراحل

\footnotetext{
${ }^{8}$ Bell and Garside
}

${ }^{9}$ Sela
مقلهمه نيشكر (Saccharum officinarum) به علت تشكيل كند سايه انداز بويزه در مراحل اوليه رشد، از سرعت رشد كمترى نسبت به ساير غلات مناطق

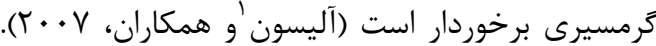
مهمترين مراحل رشدى نيشكر شامل جوانهزنى، سبز شدن و ظهور ساقه است. سبز شدن شامل يك محدوده زمانى از كاشت و ظهور جوانهها در بالاى سطح خاى بوده كه مدت آن متاثر از شرايط محيطى و خصوصيت

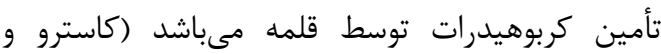

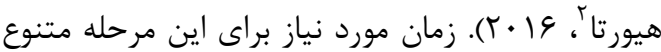

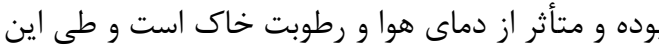

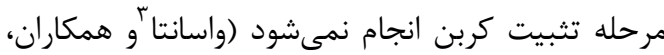

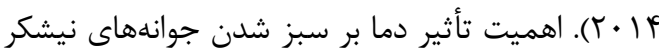
توسط ساير محققين نيز كزارش شده و بهترين دما

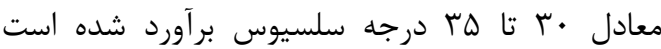

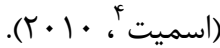

رشد و نمو برگهاى نيشكر امرى بسيار مههم در توليد و تجمع حداكثرى ماده خشك در محصول

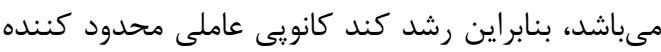

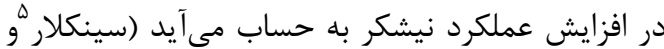

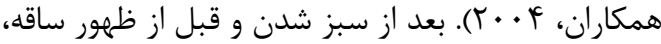
كربوهيدرات توليد شده در فتوسنتز بطور عمده به كسترش بركها و سامانه ريشهاى اختصاص مىيابد و بعد از ظهور ساقه كربوهيدرات بطور فزايندهاى بهايه تشكيل ماده خشك و تجمع شكر در ساقه تعلق مى گيرد. لذا تسهيم كربن در ييكره گياه، متناسب باده

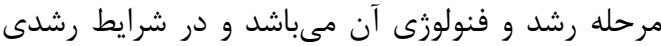
بدون تنش، افزايش طول ساقه را مىتوان به عنوان دران مرحله رشدى نيشكر در نظر كرفت (ليؤو همكاران،

.$(1991$

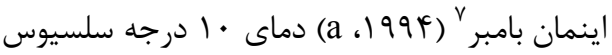

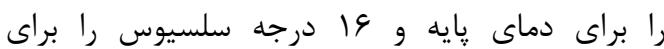

\footnotetext{
${ }^{1}$ Allison

${ }^{2}$ Castro and Huerta

${ }^{3}$ Vasantha

${ }^{4}$ Smit

${ }^{5}$ Sinclair

${ }^{6} \mathrm{Liu}$

${ }^{7}$ Inman Bamber
} 
فنولوزى مرحله كياهجهاى ارقام نيشكر در شرايط آب و هوايى جنوب خوزستان اجرا كرديد تا مناسبترين تاريخ

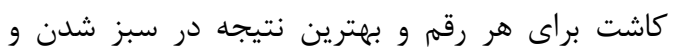
يكنواختى يوشش سبز مزرعه تعيين كردد.

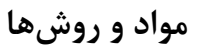

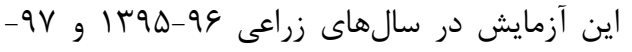
צوبا در اراضى شركت كشت و صنى صنعت نيشكر امير

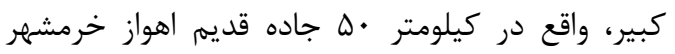

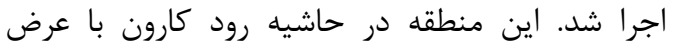

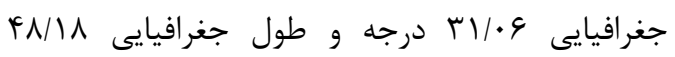
درجه و با ارتفاع V متر از سطح دريا قرار دارد. اطلاعات دمايى زمان اجراى تحقيق در جدول النشان داده شده

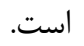

شيوه كشت بصورت جوى و يشته و كشت دو رديف

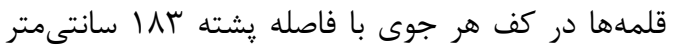

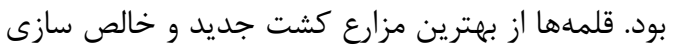
شده و بصورت دستى تهيه گرديدند. جهت كشت از

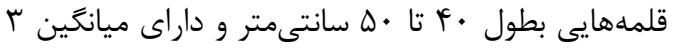

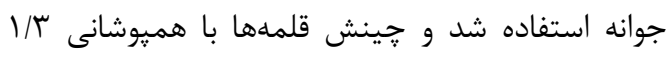

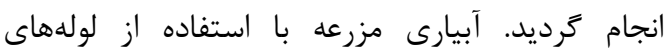

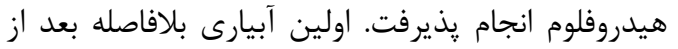

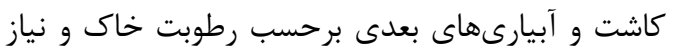

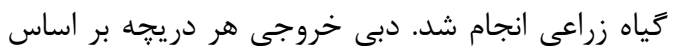

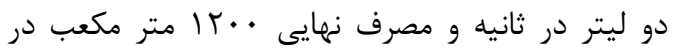

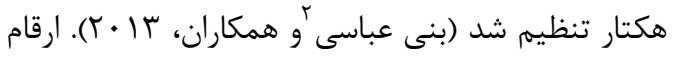

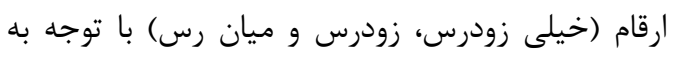
لزوم جلوكيرى از اختلاط و كستردىى محيط آزمايشى زئى

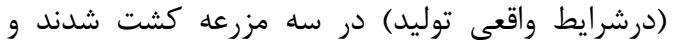

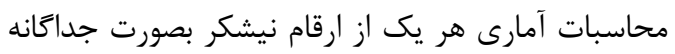

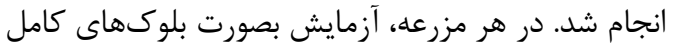

$$
\text { تصادفى و در سه تكرار اجرا شد. }
$$

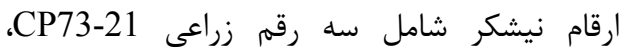
CP57-614، CP69-1062 و تاريخ كاشت شامل جهار تاريخ بيستم مرداد ماه، يكم شهريور ماه، دهم شهريور ماه و بيستم شهريور ماه بود.

\footnotetext{
${ }^{2}$ Bani Abbasi
}

رشدى، كه شامل شرايط محيطى بوده و بر فرايندهاى

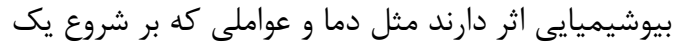

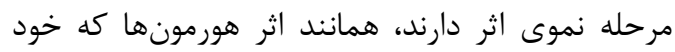

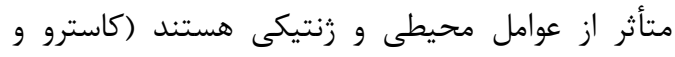

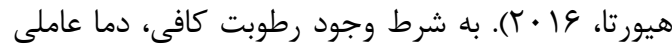
مههم در كسترش سطح برك و مهمترين عامل محيطى

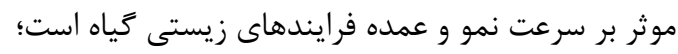
اما افزايش بيش از حد دما باعث تخريب ساختمان

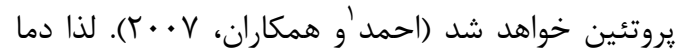

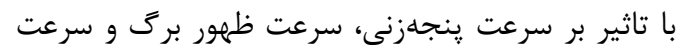

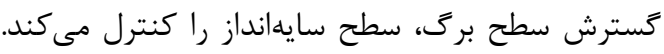

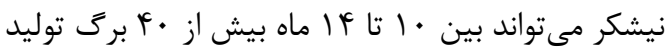

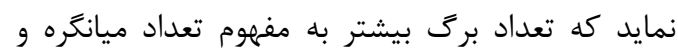

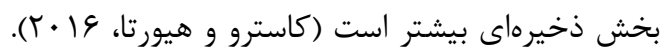

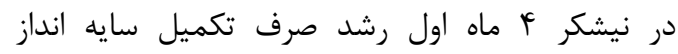

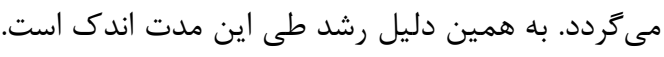

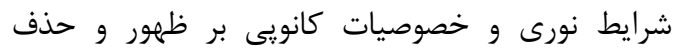
ينجهها اثركذار مىباشند. كزارش شده است كه عمده

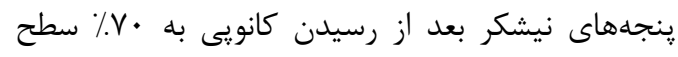

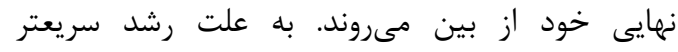

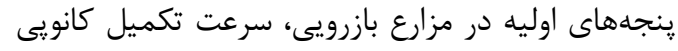
بيشتر و همجنين حذف رينجهها نيز سريعتر است

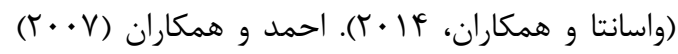
كزارش دادند كه تاريخ كشت با تأثير بر شرايط دماى همان

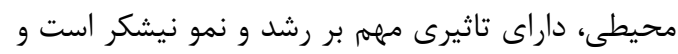

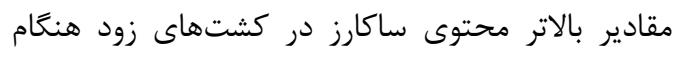
نسبت به كشتهاى با تاخير را باعث كرديد.

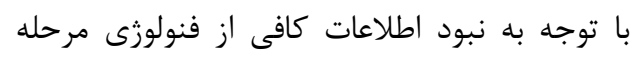

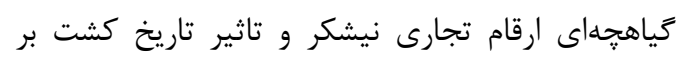

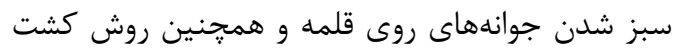

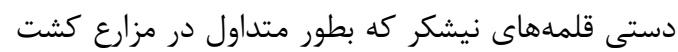

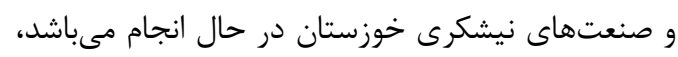
غير يكنواختى نسبى در سبز شدن مزارع قابل مشاهده از آنجاكه مرحله سبز شدن و استقرار كياهجهها پايه

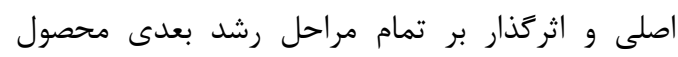

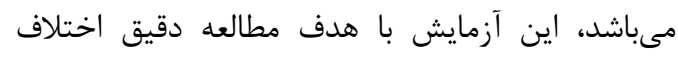

${ }^{1}$ Ahmed 
Table 1. Mean of temperature $\left({ }^{\circ} \mathrm{C}\right)$ in research implementation months

$$
\text { جدول ا. متوسط دما (درجه سلسيوس) در ماههاى اجراى تحقيق }
$$

\begin{tabular}{|c|c|c|c|c|}
\hline Month & ماه & $\begin{array}{l}\text { حداقل } \\
\text { Min }\end{array}$ & حداكثر & $\begin{array}{l}\text { Mean } \\
\text { Mيانگين }\end{array}$ \\
\hline August 2015 & مرداد هף & 25.02 & 45.37 & 35.19 \\
\hline September 2015 & شهريور ه9"1 & 22.92 & 43.17 & 33.05 \\
\hline October 2015 & 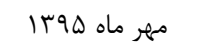 & 16.71 & 37.21 & 26.96 \\
\hline August 2016 & مرداد ماه צوץ" & 25.55 & 46.1 & 35.83 \\
\hline September 2016 & شهريور ماه צ৭با & 23.34 & 43.26 & 33.3 \\
\hline October 2016 & مهر ماه צوب1 & 18.03 & 37.87 & 27.95 \\
\hline
\end{tabular}

جدول r. خصوصيات ارقام نيشكر مورد بررسى (بنى عباسى و همكاران، سا • Y).

Table 2. Characteristics of sugarcane cultivars (Bani abbasi et al., 2013)

\begin{tabular}{|c|c|c|c|c|c|c|}
\hline رقمم & $\begin{array}{c}\text { حساسيت به آفات } \\
\text { Sensitivity to } \\
\text { pests }\end{array}$ & $\begin{array}{c}\text { حساسيت به بيمارىها } \\
\text { Sensitivity to } \\
\text { disease }\end{array}$ & $\begin{array}{c}\text { حساسيت به باد گرم } \\
\text { Warm wind } \\
\text { sensitivity }\end{array}$ & $\begin{array}{c}\text { حساسيت به سرما } \\
\text { Cold } \\
\text { sensitivity }\end{array}$ & $\begin{array}{c}\text { محتوى فيبر } \\
\text { Fiber } \\
\text { content }\end{array}$ & $\begin{array}{c}\text { طول دوره رشد } \\
\text { Growth } \\
\text { period length }\end{array}$ \\
\hline CP57-61 & Resistant & Semi sensitive & Sensitive & Semi sensitive & Medium & $\begin{array}{c}\text { Very } \\
\text { premature }\end{array}$ \\
\hline CP73-21 & Resistant & Semi resistant & Semi sensitive & Semi sensitive & Medium & Premature \\
\hline CP69-1062 & Sensitive & Resistant & Resistant & Sensitive & Low & Semi mature \\
\hline
\end{tabular}

گرديد (ليو و همكاران، 991 (1). تكميل مرحله سبز شدن

نيز در زمان سبز شدن • •ه.٪ جوانههاى كشت شده در هر

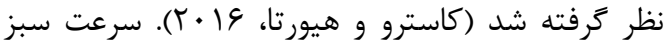

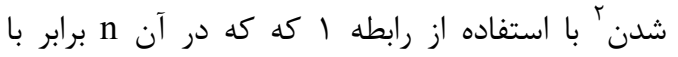

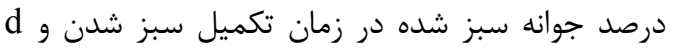
برابر با تعداد روز از كشت تا تكميل سبز شدن مىباشد

$$
\text { محاسبه شد (فروزى وَّ همكاران، ها • •r). }
$$

رابطه l:

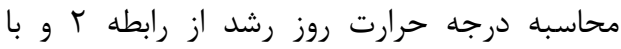

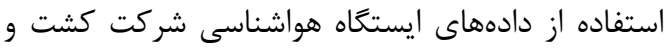

صنعت نيشكر امير كبير كه زير نظر سازمان هواشناسى

مىباشد انجام يذيرفت. محاسبه درجه حرارت روز رشد براساس دماى يايه · ل درجه سلسيوس و حداكثر دماى هr درجه سلسيوس انجام شد (آليسون و همكاران،

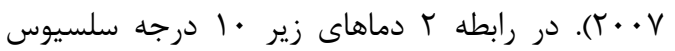

\footnotetext{
${ }^{2}$ Seedling appearance rate (SAR)

${ }^{3}$ Forouzi
}

جهت آماده سازى زمين نسبت به انجام عمليات زير

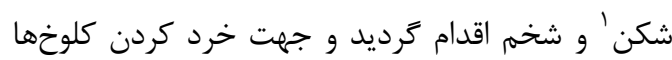
دو مرحله ديسك زده شد. سيس به منظور تسطيح زمين از ماله ليزرى استفاده شد. كود مصرفى از نوع

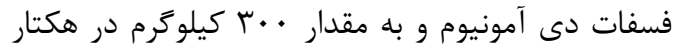
قبل از جينش قلمهها، روى رديفهاى كاشت قرار داده شد. به منظور كنترل علفهاى هرز از تركيب علفكشهاى متريبوزين و آترازين به نسبت دوبدو كيلوگرم در هكتار و بصورت يس رويشى استفاده شد (بنى عباسى و همكاران، سا • (ץ).

دو رديف اول و دو رديف انتهاى هر كرت به عنوان

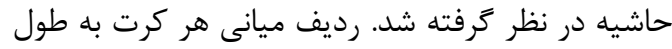
• 1 متر جهت برآورد خصوصيات سبز شدن و تغييرات تراكم در واحد سطح استفاده گرديد. تعداد جوانه سبز شده سه بار در هفته شمارش و زمان شروع سبز شدن براساس رويش حداقل يك جوانه در مترمربع لحاظ

\footnotetext{
${ }^{1}$ Sub-soiling
} 
نشان دهنده دليل تأثير يذيرى مشابه ارقام نيشكر از

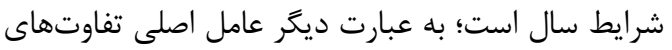

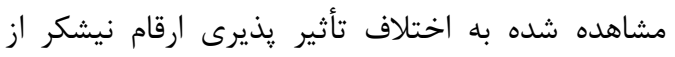

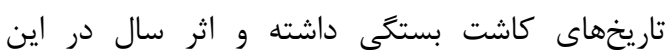

$$
\text { خصوص معنى دار نبوده است. }
$$

طبق نتايج مقايسه ميانغين (جدول \&)، تمام ارقام مورد بررسى با تأخير در كاشت با طولانى شدن زمان زمان شروع سبز شدن مواجه شدهاند. كوتاهترين زمان بين سريعترين و كندترين شروع سبز شدن در تاريخهاى

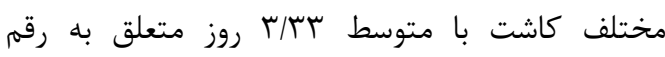

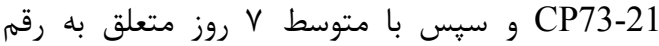
CP57-614 و در نهايت با متوسط N/IV روز به رقم باهن CP69-1062 تعلق داشت. از نظر صفت تكميل سبز شدن نيز نتايج تقريبا مشابهى حاصل شد با اين تفاوت كه تاريخ كشت بيستم مرداد ماه و يكمم شهريور ماه فاقد

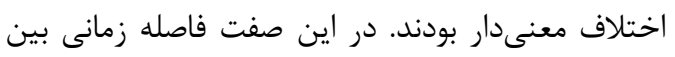
سريعترين و كندترين تكميل سبز شدن در تاريخهاى

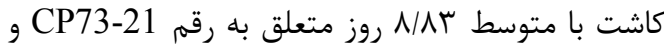

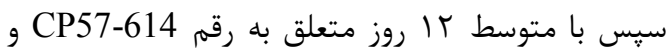

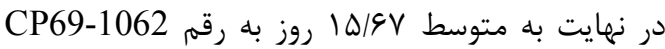

$$
\text { تعلق كرفت. }
$$

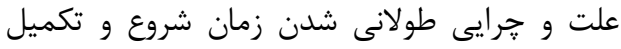

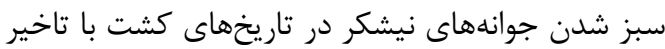
را مىتوان در نتايج صفت سرعت سبز شدن جستجو

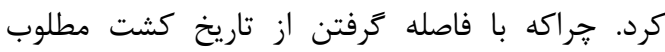

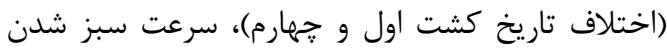

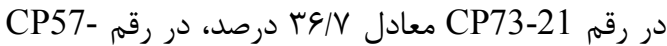

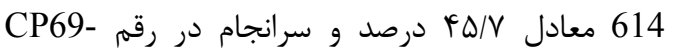

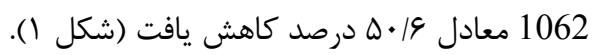

معادل · ا و دماهاى بيش از لَّ درجه سلسيوس معادل

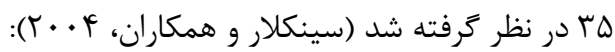

$$
\text { GDD }=\frac{\text { Tmax }+T \min }{2}-\mathrm{Tb} \quad \text { رابطه }
$$

براى تعيين تعداد برك، سطح برى، متوسط سطح تك برك و ترتيب ظهور برك با استفاده از مازيك سفيد، تعدئ بركهايى كه ليكول آنها مشخص و رشدشان ردان تكميل كرديده بود علامت و شماره كذارى كرديد (كاسترو و

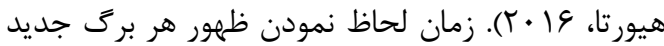
يس از نمايان شدن ليكول كه نشان دهنده باز شدن كامل آن است ملاك عمل قرار كرفت و مقايسه تيمارها

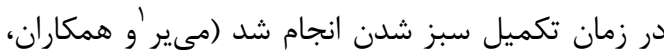

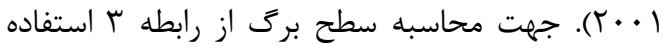

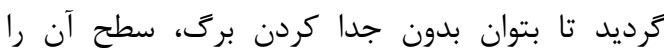

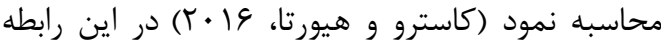

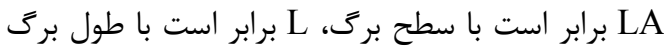

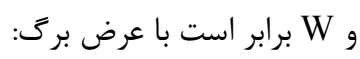

$$
\text { رابطه rا: : }
$$

انجام محاسبات آمارى با استفاده از نرمافزار SAS

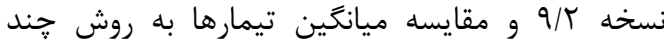
دامنهاى دانكن در سطح ه درصد انجام شد. جهت رسم نمودارها از نرم افزار

\section{نتايج و بحث}

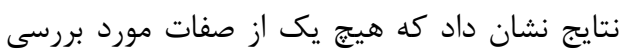
(شروع سبز شدن، تكميل سبز شدن، سرعت سبز شدن، تعداد برگ، سطح تك برك، سطح برگ كل) در مرحله كياهجهاى نيشكر متأثر از شرايط سال و اثر متقابل سال

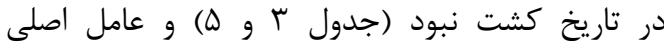
اختلاف صفات، ناشى از اثر تاريخ كشت بود.

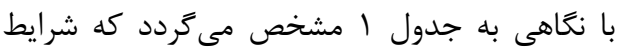

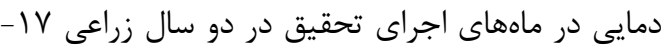

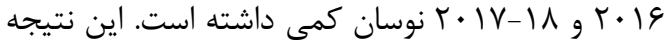

\footnotetext{
${ }^{1}$ Meiere
} 
جدول r. تجزيه واريانس (ميانكين مربعات) اثر سال و تاريخ كاشت بر صفات شروع سبز شدن، تكميل سبز شدن و سرعت سبز شدن ارقام زراعى

Table 3. Analysis of variance (Mean Square) for effect of annual and planting date on emergence beginning, emergence completion and emergence rate of sugarcane cultivars

\begin{tabular}{|c|c|c|c|c|c|c|c|c|c|c|}
\hline \multirow{2}{*}{ 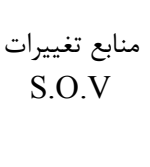 } & \multirow{2}{*}{$\begin{array}{l}\text { درجه } \\
\text { آزادى } \\
\text { df }\end{array}$} & \multicolumn{3}{|c|}{$\begin{array}{c}\text { سرعت سبز شدن } \\
\text { Emergence rate }\end{array}$} & \multicolumn{3}{|c|}{$\begin{array}{c}\text { تكميل سبز شدن } \\
\text { Emergence completion }\end{array}$} & \multicolumn{3}{|c|}{$\begin{array}{c}\text { شروع سبز شدن } \\
\text { Emergence beginning }\end{array}$} \\
\hline & & $\begin{array}{c}\text { CP69- } \\
1062\end{array}$ & $\begin{array}{c}\text { CP57- } \\
614\end{array}$ & $\begin{array}{c}\text { CP73- } \\
21\end{array}$ & $\begin{array}{c}\text { CP69- } \\
1062\end{array}$ & $\begin{array}{c}\text { CP57- } \\
614\end{array}$ & $\begin{array}{c}\text { CP73- } \\
21\end{array}$ & $\begin{array}{c}\text { CP69- } \\
1062\end{array}$ & $\begin{array}{c}\text { CP57- } \\
614\end{array}$ & CP73-21 \\
\hline $\begin{array}{c}\text { سال } \\
\text { Year }\end{array}$ & 1 & $0.01^{\mathrm{ns}}$ & $0.1^{\mathrm{ns}}$ & $0.052^{\mathrm{ns}}$ & $5.041^{\mathrm{ns}}$ & $1.5^{\mathrm{ns}}$ & $2.04^{\mathrm{ns}}$ & $0.666^{\mathrm{ns}}$ & $0.166^{\mathrm{ns}}$ & $0.66^{\mathrm{ns}}$ \\
\hline $\begin{array}{c}\text { بلوك (سال) } \\
\text { Block } \\
\text { (year) }\end{array}$ & 4 & 0.048 & 0.058 & 0.021 & 3.45 & 3.33 & 0.29 & 0.916 & 0.333 & 0.16 \\
\hline $\begin{array}{c}\text { تاريخ كاشت } \\
\text { Planting } \\
\text { date }\end{array}$ & 3 & $3.69^{* *}$ & $3.16^{* *}$ & $1.65^{*}$ & $316.93^{* *}$ & $178.1^{* *}$ & $90.15^{* *}$ & $84.55^{* *}$ & $62.44^{* *}$ & $13.5^{* *}$ \\
\hline $\begin{array}{c}\text { كاشت×سال } \\
\text { Planting } \\
\text { date×year }\end{array}$ & 3 & $0.035^{\mathrm{ns}}$ & $0.035^{\mathrm{ns}}$ & $0.069^{\text {ns }}$ & $4.26^{\mathrm{ns}}$ & $1.61^{\mathrm{ns}}$ & $2.37^{\mathrm{ns}}$ & $0.111^{\mathrm{ns}}$ & $0.166^{\mathrm{ns}}$ & $2.329 \mathrm{e}-31^{\mathrm{ns}}$ \\
\hline $\begin{array}{c}\text { خ } \\
\text { Error }\end{array}$ & 12 & 0.014 & 0.024 & 0.046 & 1.68 & 1.61 & 1.84 & 0.583 & 0.388 & 0.777 \\
\hline $\begin{array}{c}\text { ضريبرات (\%) } \\
\text { CV (\%) }\end{array}$ & - & 4.79 & 5.86 & 7.93 & 5.92 & 6.39 & 7.16 & 4.87 & 4.45 & 6.96 \\
\hline
\end{tabular}

$$
\text { جدول F. مقايسه ميانكَين اثر تاريخ كشت براى صفات شروع سبز شدن، تكميل سبز شدن و سرعت سبز شدن ارقام زراعى نيشكر }
$$

Table 4. Mean comparison of effect of planting date on emergence beginning, emergence completion and emergence rate of sugarcane cultivars

\begin{tabular}{|c|c|c|c|c|c|c|c|c|c|}
\hline \multirow{2}{*}{$\begin{array}{c}\text { تاريخ كاشت } \\
\text { Planting Date }\end{array}$} & \multicolumn{3}{|c|}{$\begin{array}{c}\text { سرعت سبز شدن (كياه در روز) } \\
\text { Emergence rate } \\
\text { (plant/day) }\end{array}$} & \multicolumn{3}{|c|}{$\begin{array}{c}\text { تكميل سبز شدن (روز) } \\
\text { Emergence completion } \\
\text { (day) }\end{array}$} & \multicolumn{3}{|c|}{$\begin{array}{c}\text { شروع سبز شدن (روز) } \\
\text { emergence beginning } \\
\text { (day) }\end{array}$} \\
\hline & $\begin{array}{c}\text { CP69- } \\
1062\end{array}$ & $\begin{array}{l}\text { CP57- } \\
614\end{array}$ & $\begin{array}{c}\text { CP73- } \\
21\end{array}$ & $\begin{array}{c}\text { CP69- } \\
1062\end{array}$ & $\begin{array}{c}\text { CP57- } \\
614\end{array}$ & $\begin{array}{c}\text { CP73- } \\
21\end{array}$ & $\begin{array}{c}\text { CP69- } \\
1062\end{array}$ & $\begin{array}{c}\text { CP57- } \\
614\end{array}$ & $\begin{array}{l}\text { CP73- } \\
21\end{array}$ \\
\hline $\begin{array}{l}\text { بيستم مرداد } 11^{\text {rd }} \\
\text { Aug }\end{array}$ & $3.3^{\mathrm{a}}$ & $3.5^{\mathrm{a}}$ & $3.27^{\mathrm{a}}$ & $15.16^{\mathrm{a}}$ & $14.33^{\mathrm{a}}$ & $15.33^{\mathrm{a}}$ & $11.83^{\mathrm{a}}$ & $10.5^{\mathrm{a}}$ & $11.5^{\mathrm{a}}$ \\
\hline $\begin{array}{l}\text { Aug } 23^{\text {rd }} \text { شهريور } \\
\text { Ad }\end{array}$ & $2.97^{\mathrm{a}}$ & $3.04^{\mathrm{b}}$ & $2.99^{\mathrm{ab}}$ & $16.83^{\mathrm{a}}$ & $16.5^{\mathrm{a}}$ & $16.83^{\mathrm{ab}}$ & $13.33^{\mathrm{b}}$ & $12.16^{\mathrm{b}}$ & $11.83^{\mathrm{b}}$ \\
\hline $\begin{array}{l}\text { دهم شهريور } \\
\text { Sep } 1^{\text {rd }}\end{array}$ & $2.03^{b}$ & $2.25^{\mathrm{c}}$ & $2.57^{\mathrm{b}}$ & $24.66^{\mathrm{b}}$ & $22.16^{\mathrm{b}}$ & $19.5^{\mathrm{b}}$ & $17.5^{\mathrm{c}}$ & $15.83^{\mathrm{c}}$ & $12.5^{\mathrm{c}}$ \\
\hline 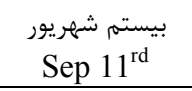 & $1.63^{\mathrm{c}}$ & $1.9^{\mathrm{d}}$ & $2.07^{\mathrm{c}}$ & $30.83^{c}$ & $26.33^{c}$ & $24.16^{\mathrm{c}}$ & $20^{\mathrm{d}}$ & $17.5^{\mathrm{d}}$ & $14.83^{\mathrm{d}}$ \\
\hline
\end{tabular}

In each column the means with the same letters have no significant difference at the level of 5\%. 


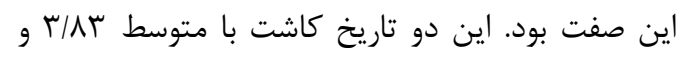

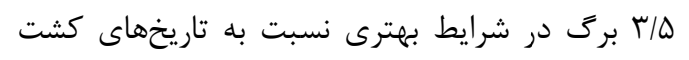

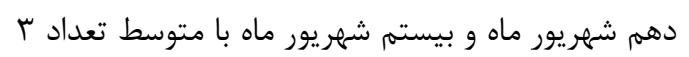

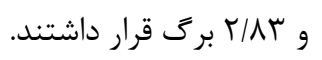

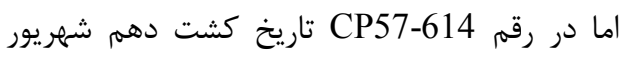

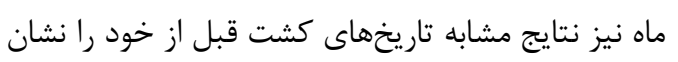

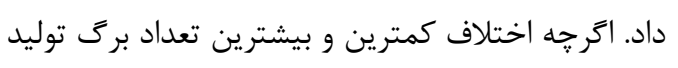

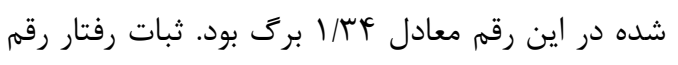

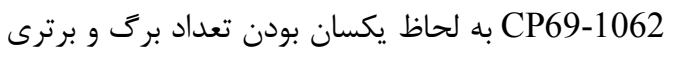

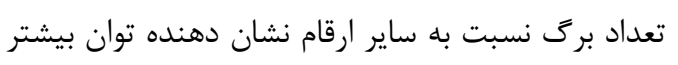

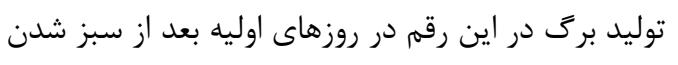
بود؛ به عبارت ديكر رقم 1062-10969 با توانايى بيشتر

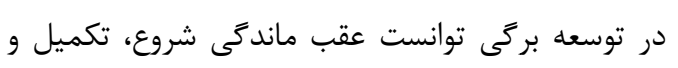
سرعت سبز شدن خود را در تاريخهاى كشت بـ بانس تأخير

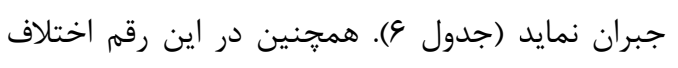

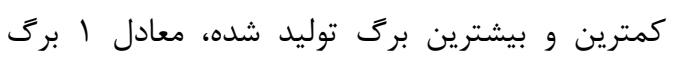

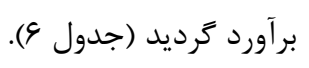
با بررسى نتايج مقايسه ميانخين اثر تاريخ كاشت بر برد

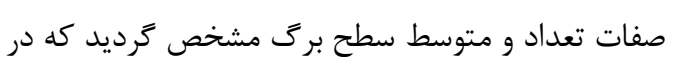

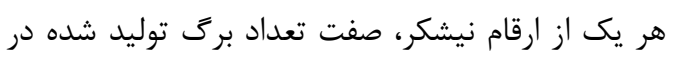

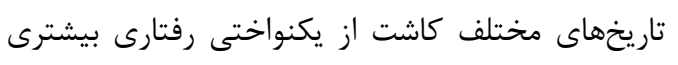

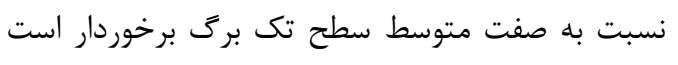

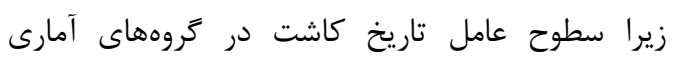

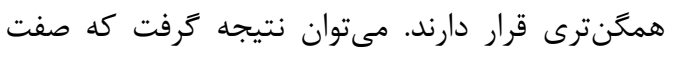
متوسط سطح برى نيشكر نسبت به تأخير در كاشت ندان حساستر از صفت تعداد برى است.

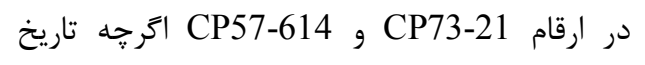
كاشت يكم شهريور ماه در تعداد برى به به بيستم مرداد

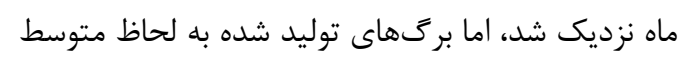

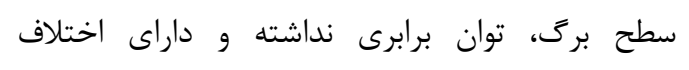

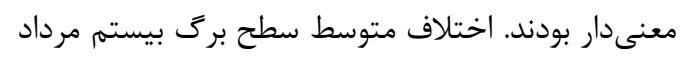

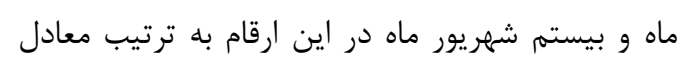

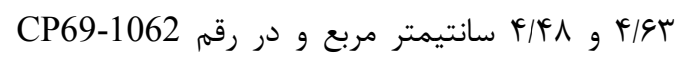

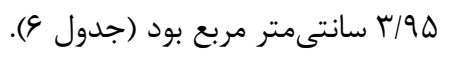

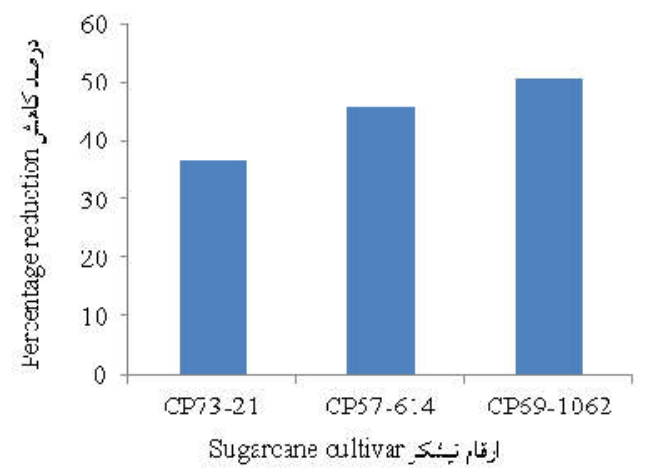

شكل ا. مقايسه درصد كاهش سرعت سبز شدن در تاريخ كشت بيستم شهريور ماه نسبت به بيستم مرداد ماه

Fig. 1. Comparison of the percentage of emergence rate on Sep $11^{\text {th }}$ to Sep $11^{\text {th }}$

اين نتايج نشان دهنده يكنواختى بيشتر صفات سبز

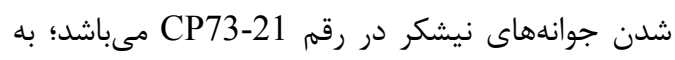

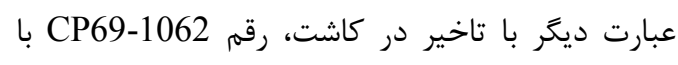

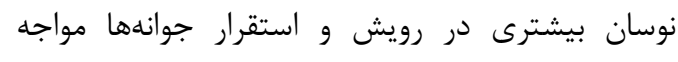

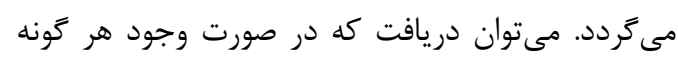

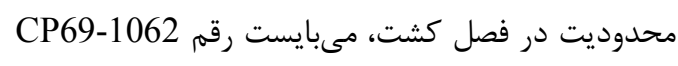

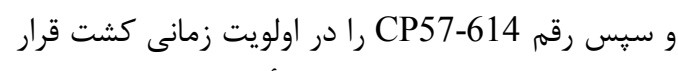
داد. كزارش بسيارى از محققين تأييد مى كند كه تاخير

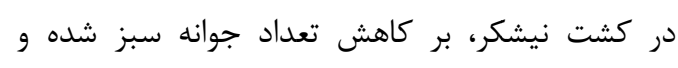

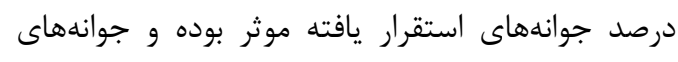

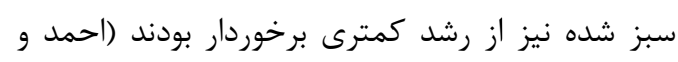

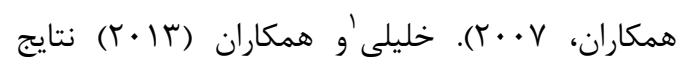

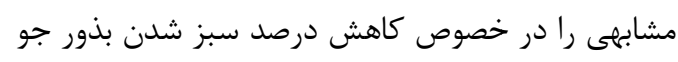

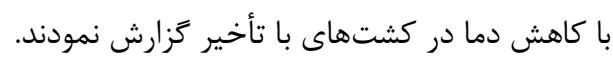

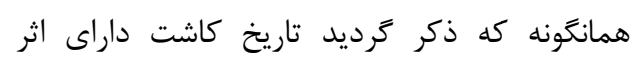
معنى دارى بر صفات توسعه بركى نيشكر بود؛ اما مشاهده

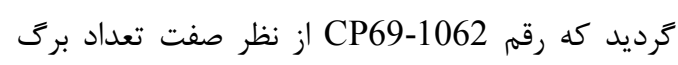

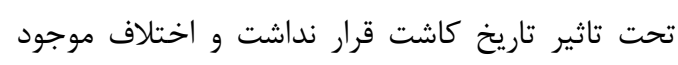

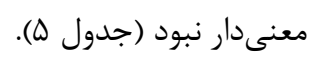

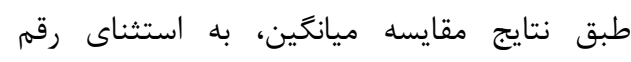

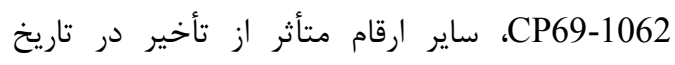

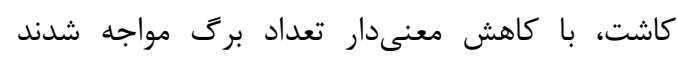

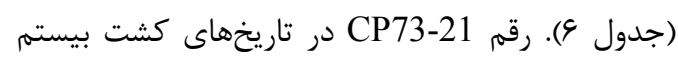

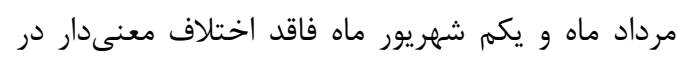

${ }^{1}$ Khalili 
جدول ه. تجزيه واريانس (ميانكين مربعات) اثر سال و تاريخ كاشت براى صفات تعداد برك، سطح تك برك، سطح برك كل ارقام زراعى نيشكر

Table 5. Analysis of variance (Mean Square) for effect of annual and planting date on leaf number, mean of leaf area and total leaf area of sugarcane cultivars

\begin{tabular}{|c|c|c|c|c|c|c|c|c|c|c|}
\hline \multirow{2}{*}{$\begin{array}{l}\text { منابع تغييرات } \\
\text { S.O.V }\end{array}$} & \multirow{2}{*}{$\begin{array}{c}\text { داز درجه } \\
\text { df }\end{array}$} & \multicolumn{3}{|c|}{$\begin{array}{c}\text { سطح برك كل } \\
\text { Total leaf area }\end{array}$} & \multicolumn{3}{|c|}{$\begin{array}{c}\text { متوسط سطح برك } \\
\text { Mean of leaf area }\end{array}$} & \multicolumn{3}{|c|}{$\begin{array}{c}\text { تعداد برك } \\
\text { Leaf number }\end{array}$} \\
\hline & & $\begin{array}{l}\text { CP69- } \\
1062\end{array}$ & $\begin{array}{l}\text { CP57- } \\
614\end{array}$ & $\begin{array}{l}\text { CP73- } \\
21\end{array}$ & $\begin{array}{l}\text { CP69- } \\
1062\end{array}$ & $\begin{array}{l}\text { CP57- } \\
614\end{array}$ & $\begin{array}{l}\text { CP73- } \\
21\end{array}$ & $\begin{array}{c}\text { CP69- } \\
1062\end{array}$ & $\begin{array}{l}\text { CP57- } \\
614\end{array}$ & $\begin{array}{l}\text { CP73- } \\
21\end{array}$ \\
\hline $\begin{array}{l}\text { سال } \\
\text { Year }\end{array}$ & 1 & $30.37^{\mathrm{ns}}$ & $1.7^{\mathrm{ns}}$ & $21.47^{\mathrm{ns}}$ & $0.01^{\mathrm{ns}}$ & $1.76^{\mathrm{ns}}$ & $0.126^{\mathrm{ns}}$ & $0.375^{\mathrm{ns}}$ & $0.166^{\mathrm{ns}}$ & $0.375^{\mathrm{ns}}$ \\
\hline $\begin{array}{c}\text { بلوك (سال) } \\
\text { Block (year) }\end{array}$ & 4 & 5.71 & 33.14 & 9.62 & 0.05 & 0.332 & 0.0829 & 0.083 & 0.416 & 0.208 \\
\hline $\begin{array}{l}\text { تاريخ كاشت } \\
\text { Planting date }\end{array}$ & 3 & $663.17^{*}$ & $630.47^{* *}$ & $613.88^{* *}$ & $21.54^{* *}$ & $23.29^{* *}$ & $25.85^{* *}$ & $0.819^{\mathrm{ns}}$ & $1.94^{*}$ & $1.26^{* *}$ \\
\hline $\begin{array}{c}\text { تاريخ كاشت ×سال } \text { × year } \\
\text { Planting date }\end{array}$ & 3 & $46.58^{\mathrm{ns}}$ & $6.32^{\mathrm{ns}}$ & $2.87^{\mathrm{ns}}$ & $0.56^{\mathrm{ns}}$ & $0.155^{\mathrm{ns}}$ & $0.16^{\mathrm{ns}}$ & $0.375^{\mathrm{ns}}$ & $0.166^{\mathrm{ns}}$ & $0.041^{\mathrm{ns}}$ \\
\hline $\begin{array}{l}\text { خ } \\
\text { Error }\end{array}$ & 12 & 47.39 & 30.27 & 32.71 & 0.21 & 0.849 & 0.385 & 0.472 & 0.305 & 0.319 \\
\hline $\begin{array}{l}\text { ضريب تغييرات } \\
\quad \text { CV\% }\end{array}$ & - & 24.71 & 22.1 & 25 & 7.09 & 13.12 & 9.29 & 16.32 & 16.17 & 17.17 \\
\hline
\end{tabular}

جدول 9. مقايسه ميانكين اثر تاريخ كاشت براى صفات توسعه بركى كياهحههاى ارقام نيشكر

Table 6. Means comparison of effect of planting date on leaf expansion of sugarcane seedling cultivars

\begin{tabular}{|c|c|c|c|c|c|c|c|c|c|}
\hline \multirow{2}{*}{$\begin{array}{c}\text { تاريخ كاشت } \\
\text { Planting } \\
\text { date }\end{array}$} & \multicolumn{3}{|c|}{ سطح برك كل (سانتىمتر مربع) } & \multicolumn{3}{|c|}{$\begin{array}{c}\text { متوسط سطح برك (سانتىمتر مربع) } \\
\text { Mean of leaf area }\left(\mathrm{cm}^{2}\right)\end{array}$} & \multicolumn{3}{|c|}{$\begin{array}{c}\text { تعداد برك } \\
\text { Leaf number }\end{array}$} \\
\hline & $\begin{array}{l}\text { CP69- } \\
1062\end{array}$ & $\begin{array}{c}\text { CP57- } \\
614\end{array}$ & CP73-21 & $\begin{array}{l}\text { CP69- } \\
1062\end{array}$ & $\begin{array}{l}\text { CP57- } \\
614\end{array}$ & $\begin{array}{c}\text { CP73- } \\
21\end{array}$ & $\begin{array}{l}\text { CP69- } \\
1062\end{array}$ & $\begin{array}{c}\text { CP57- } \\
614\end{array}$ & $\begin{array}{c}\text { CP73- } \\
21\end{array}$ \\
\hline $\begin{array}{l}\text { بيسته مرداد } 11^{\text {rd }} \\
\text { Aug } 1{ }^{\text {rd }}\end{array}$ & $39.5^{\mathrm{a}}$ & $36.13^{\mathrm{a}}$ & $35.61^{\mathrm{a}}$ & $8.38^{\mathrm{a}}$ & $9.06^{\mathrm{a}}$ & $9.23^{\mathrm{a}}$ & $4.66^{\mathrm{a}}$ & $4^{a}$ & $3.83^{\mathrm{a}}$ \\
\hline $\begin{array}{l}\text { Aug } 23^{\text {rd }} \text { شهريور }\end{array}$ & $33.7^{\mathrm{ab}}$ & $29.5^{\mathrm{b}}$ & $26.13^{\mathrm{b}}$ & $7.73^{\mathrm{a}}$ & $8.06^{\mathrm{b}}$ & $7.43^{\mathrm{b}}$ & $4.33^{\mathrm{a}}$ & $3.66^{\mathrm{a}}$ & $3.5^{\mathrm{a}}$ \\
\hline $\begin{array}{l}\text { دهم شهريور } \\
\text { Sep } 1^{\text {rd }}\end{array}$ & $21.25^{b c}$ & $21.55^{\mathrm{c}}$ & $16.65^{\mathrm{c}}$ & $5.3^{\mathrm{b}}$ & $6.36^{\mathrm{c}}$ & $5.45^{\mathrm{c}}$ & $4^{a}$ & $3.33^{\mathrm{ab}}$ & $3^{\mathrm{b}}$ \\
\hline بيستم شهريور & $16.98^{\mathrm{c}}$ & $12.38^{\mathrm{d}}$ & $13.11^{\mathrm{d}}$ & $4.43^{\mathrm{b}}$ & $4.58^{\mathrm{d}}$ & $4.6^{\mathrm{c}}$ & $3.83^{\mathrm{a}}$ & $2.66^{\mathrm{b}}$ & $2.83^{\mathrm{b}}$ \\
\hline
\end{tabular}

In each column the means with the same letters have no significant difference at the level of $5 \%$.

سطح برى كل نيز از اختلاف آمارى كمترى در تاريخهاى مختلف كاشت برخوردار باشد. بويزه اينكه

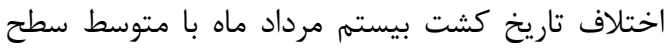

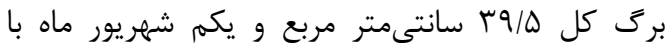
متوسط T/V T/T سانتىمتر مربع معنى دار نشد؛ اما در ارقام CP73-21 , CP57-614 اختلاف تمام تاريخهاى كاشت معنىدار و كاهشى بود (جدول و). با توجه به تأثير قابل توجه دما بر رشد بركَ برهاى نيشكر، علت

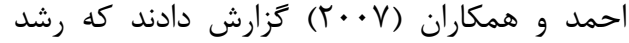

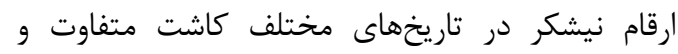
معنى دار بود، اما اختلاف صفات رشدى رقم - LCP85

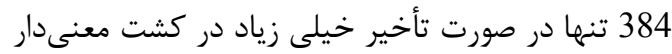

رقم CP69-1062 به علت عملكرد مناسب و با ثباتتر در سطوح مختلف تاريخ كاشت در دو صفت تعداد برگ و متوسط سطح تك برى، توانست در صفت 
جذب حداكثرى انرزى خورشيدى به علت توسعه بيشتر سايهانداز در تاريخ كشت مناسب مىداند. اين نتيجه توسط ساير محققين نيز مورد تأييد قرار گرفته است

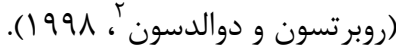

معادلات شروع، تكميل و و سرعت سبز شدون شون جوانههاى ارقام تجارى نيشكر مورد مطالعه در تاريخهاى

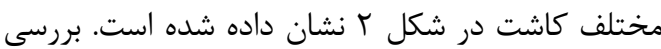
معادلات مشخص كرد كه روند تغيير صفت تكميل سبز شدن در همه ارقام زراعى نيشكر مورد بررسى بر معادله

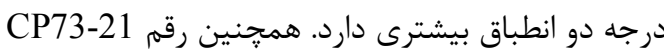
در هر سه صفت شروع، تكميل و سرعت سبز شدن جوانهها از معادله درجه دو تبعيت نمود؛ اما روند CP57- تغييرات صفات شروع و سرعت سبز شدن ارقام 614 و CP69-1062 بر مدل خطى انطباق داشت. بر اساس نتايج كزارش شده توسط لايورَّو همكاران (1999) تاريخ كاشت بر ميزان و سرعت رشد نيشكر اثر حذار بود و علت آن را تاثير تاريخ كشت بر رزيم دمايى و ميزان نور دريافتى توسط گياه زراعى دانست.

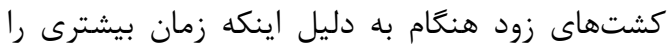
براى استفاده از منابع محيطى مانند نور و دما در اختيار بوتهاى نيشكر قرار مى دهند، نسبت به تاريخ كشتهاى دير هنگَام، برترى دارند، زيرا در اين وضعيت يِيش از وقوع سرما، مرحله سبز شدن و استقرار بوتهها به يايان مىرسد. بسيارى از محققين سرعت رشد برى را عمده

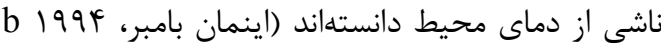

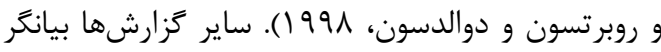
سرعت رشد بالاتر برگهاى اوليه نيشكر به دون، دليل بهرهمندى از دماى تجمعى بالاتر محيطى است. طبق

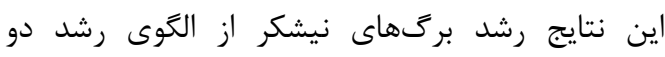
مرحلهاى ييروى مىنمايد و هر دو مرحله بر مدل رشد

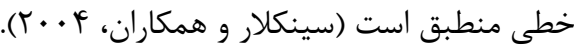
مقادير درجه روز رشد مورد نياز شروع و تكميل سبز

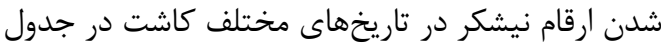
نشان داده شده است. همانگونه كه مشاهده مى گر دد، در تمام ارقام مورد بررسى و در تاريخهاى مختلف كاشت، همزمان با افزايش طول دوره شروع و تكميل

\footnotetext{
${ }^{2}$ Robertson and Doualdson

${ }^{3}$ Laure
}

كاهش شاخصهاى توسعه برى در كشتهاى با تأخير را مىتوان ناشى از افت دما در روزهاى اوليه ياييز دانست. درحاليكه فراهم بودن دماى مناسب سبز شدن و رشد گياهجه ها و شرايط مطلوب توسعه سطح برى به برترى

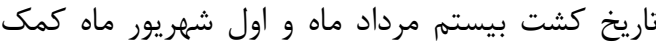

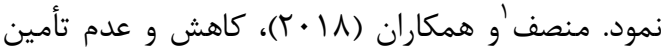
درجه حرارت كافى را عامل اصلى كاهش تعداد برگ و سطح برى در تاريخ كشت با تأخير گزارش كرد. با نَاهى به تغييرات اثر تاريخهاى كاشت و اختلاف آنها در دو صفت تعداد برى و متوسط سطح تك برى مشخص شد كه سطح برى كل بوتههاى نيشكر بيش از آنكه متاثر از تعداد برگ باشد، از متوسط سطح برى

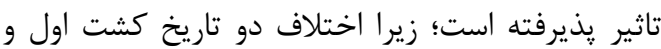
دو تاريخ كشت دوم در صفت تعداد برى معنى دار نبود و

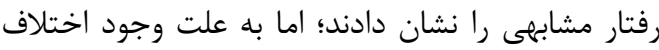
تاريخهاى معنىدار در متوسط سطح برگ، اختلاف تاريخهاى كاشت از نظر سطح برى كل معنى مار شدى شد.

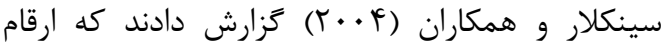
نيشكر كشت شده در سه منطقه مختلف از نظر سطح تك برگ، سطح برى كل و تعداد برگ اختلاف معنىدارى داشتند كه با يافتههاى اين تحقيق مطابقت

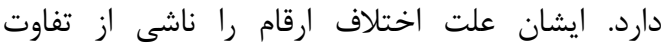

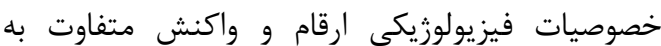

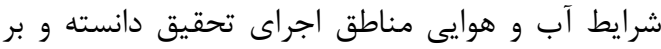
اين اساس ارقام نيشكر را براى مناطق حارهاى و معتدل

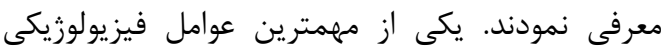
موثر بر رشد گَياجههاى نيشكر، قابليت تأمين مواد غذايى توسط قلمه در ابتداى رشد است. ارقامى كه از توانايى بيشترى در اين خصوص برخوردار باشند در برسيط ابتداى فصل كشت با رشد بهتر و در صورت تأخير در كشت، با افت رشد كمترى مواجه خواهند شد. طبق نتايج جدول مقايسه ميانگين، سطح برى كل تاريخ كشت بيستم مرداد ماه نسبت به بيستم شهريور ماه به ترتيب در ارقام CP73-21،

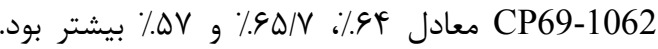

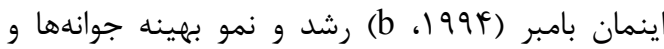
افزايش تجمع ماده خشك در بوتههاى نيشكر را ناشى از

${ }^{1}$ Munsif 
شروع سبز شدن (روز)

Emergence beginning (day)

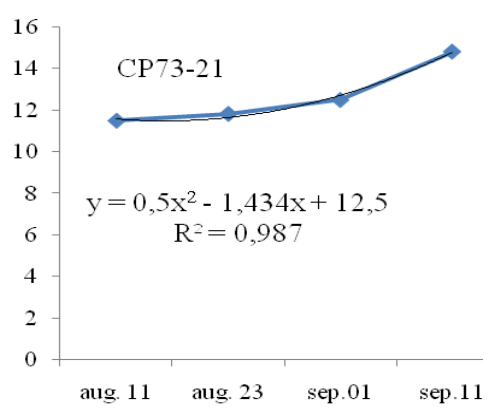

Planting date
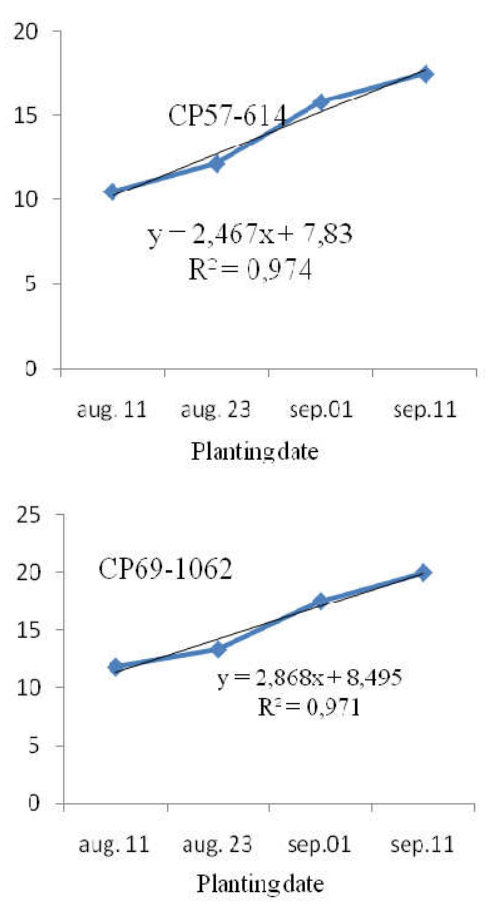

تكميل سبز شدن (روز)

Emergence completion (day)

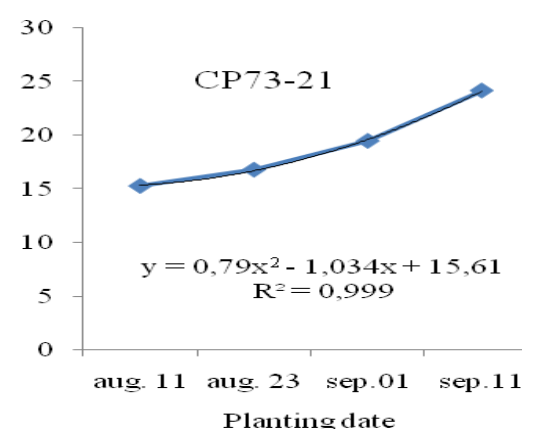

Planting date
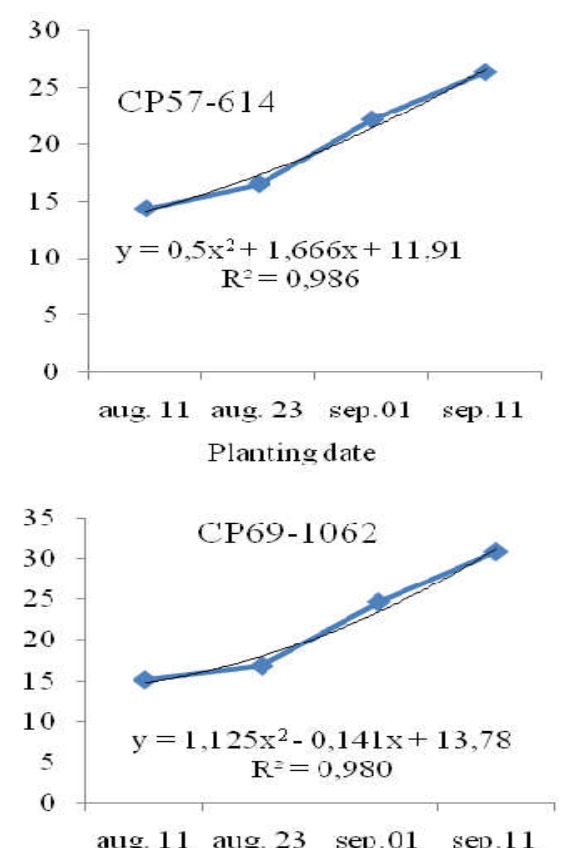

Planting date
سرعت سبز شدن (كياه/روز)

Emergence rate (plant/day)
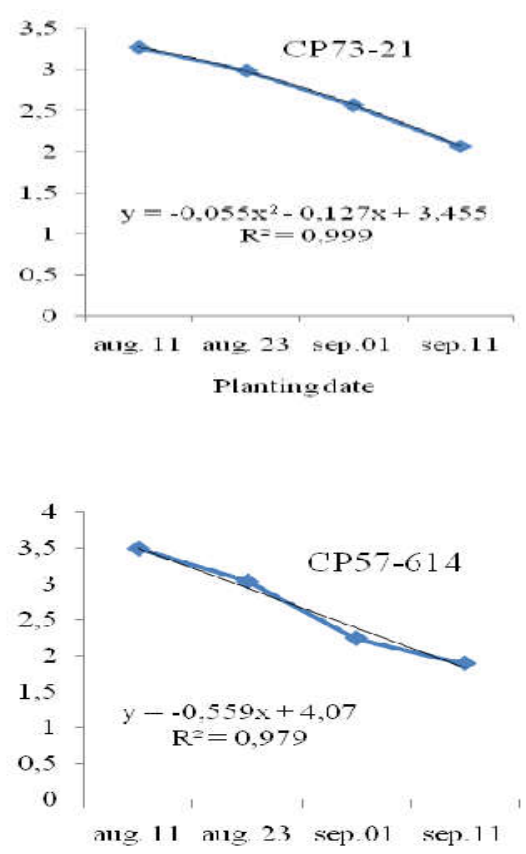

Planting date

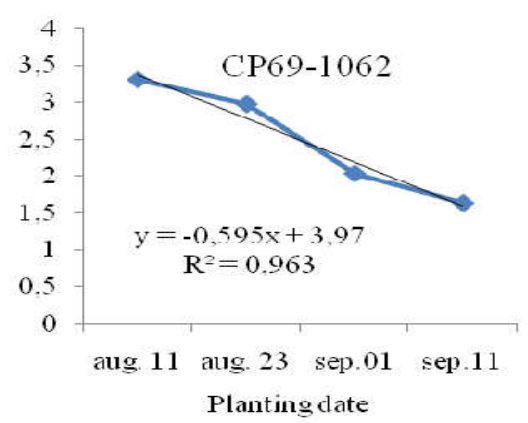

شكل r. معادلات زمان شروع، تكميل و سرعت سبز شدن جوانههاى ارقام تجارى نيشكر در تاريخهاى مختلف كاشت

Fig. 1. Regression of emergence beginning, emergence completion and emergence rate of sugarcane cultivars on different planting dates 


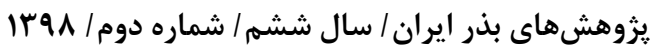

جدول Vا. درجه روز رشد مورد نياز شروع و تكميل سبز شدن ارقام نيشكر در تاريخهاى مختلف كاشت

Table 7. GDD requirement of emergence beginning and emergence completion of sugarcane cultivars on different planting dates

\begin{tabular}{|c|c|c|c|c|c|}
\hline \multirow{2}{*}{$\begin{array}{c}\text { رقم } \\
\text { Cultivar }\end{array}$} & \multirow{2}{*}{$\begin{array}{c}\text { تاريخ كشت } \\
\text { Planting Date }\end{array}$} & \multicolumn{2}{|c|}{$\begin{array}{c}\text { شروع سبز شدن } \\
\text { Emergence beginning }\end{array}$} & \multicolumn{2}{|c|}{$\begin{array}{c}\text { تكميل سبز شدن } \\
\text { Emergence completion }\end{array}$} \\
\hline & & $\begin{array}{c}\text { روز بعد از كاشت } \\
\text { Day after planting } \\
\end{array}$ & $\begin{array}{l}\text { GDD } \\
\left(\mathrm{C}^{\circ}\right)\end{array}$ & $\begin{array}{c}\text { روز بعد از كاشت } \\
\text { Day after planting }\end{array}$ & $\begin{array}{l}\text { GDD } \\
\left(\mathrm{C}^{\circ}\right)\end{array}$ \\
\hline \multirow{5}{*}{ CP73-21 } & Aug $11^{\text {rd }}$ & 11.5 & 231.8 & 15.33 & 306.3 \\
\hline & Aug $23^{\text {rd }}$ & 11.83 & 237.5 & 16.83 & 336.4 \\
\hline & mean of Aug $11^{\text {rd }}$ and Aug $23^{\text {rd }}$ & 11.66 & 235.9 & 16.08 & 321.35 \\
\hline & Sep $1^{\text {rd }}$ & 12.5 & 240 & 19.5 & 364.8 \\
\hline & Sep $11^{\text {rd }}$ & 14.83 & 264 & 24.16 & 421.2 \\
\hline \multicolumn{2}{|c|}{ Mean of all planting dates } & 12.66 & 243.4 & 18.95 & 357.2 \\
\hline \multirow{5}{*}{ CP57-614 } & Aug $11^{\text {rd }}$ & 10.5 & 212.8 & 14.33 & 289.7 \\
\hline & Aug $23^{\text {rd }}$ & 12.16 & 246.4 & 16.5 & 330.4 \\
\hline & Mean of Aug $11^{\text {rd }}$ and Aug $23^{\text {rd }}$ & 11.33 & 229.6 & 15.41 & 310.05 \\
\hline & Sep $1^{\text {rd }}$ & 15.83 & 293.7 & 22.16 & 409.8 \\
\hline & Sep $11^{\text {rd }}$ & 17.5 & 310 & 26.33 & 454.9 \\
\hline \multicolumn{2}{|c|}{ Mean of all planting dates } & 13.99 & 265.7 & 19.83 & 371.2 \\
\hline \multirow{6}{*}{ СР69-1062 } & Aug $11^{\text {rd }}$ & 11.83 & 238.1 & 15.16 & 305.9 \\
\hline & Aug $23^{\text {rd }}$ & 13.33 & 268.4 & 16.83 & 333 \\
\hline & Mean of Aug $11^{\text {rd }}$ and Aug $23^{\text {rd }}$ & 12.58 & 253.25 & 15.99 & 319.45 \\
\hline & Sep $1^{\text {rd }}$ & 17.5 & 327.5 & 24.66 & 453.4 \\
\hline & Sep $11^{\text {rd }}$ & 20 & 354.1 & 30.83 & 527.2 \\
\hline & an of all planting dates & 15.66 & 297 & 21.87 & 404.9 \\
\hline
\end{tabular}

نياز خود را در مدت زمان طولانىترى دريافت كرده و در

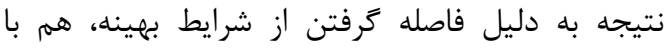

تأخير در رشد و هم كاهش در شاخصهاى رشد مواجه

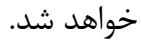

نتايج گزارش شده توسط آنايالى وُ همكاران (ه • • (؟)

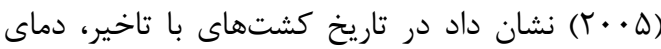

بالا در ابتداى مراحل رشد رويشى باعث كاهش مدت

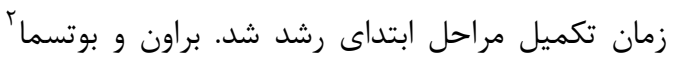

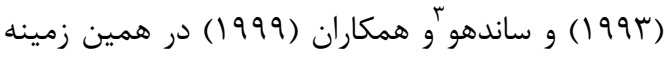

$$
\text { نتايج مشابهى را گَزارش كردند. }
$$

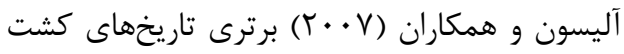

\footnotetext{
${ }^{1}$ Anapalli

${ }^{2}$ Brown and Bootsmam

${ }^{3}$ Sandhu
}

مرحله سبز شدن، درجه روز رشد مورد نياز افزايش يافته است. مقايسه بين ارقام نيز نشان دهنده اختلاف درجه حرارتهاى مورد نياز آنها بود. طبق نتايج بدست آمده، رقم CP73-21 با ميانگين

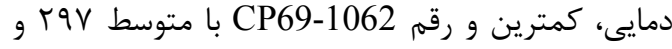

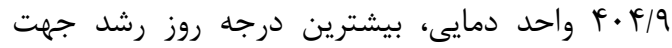

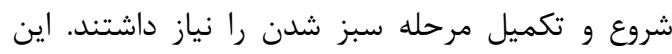
مقادير براى رقم CP57-614 به ترتيب برابر \$ \$ \$ و و

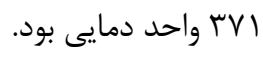

جنانجه نيشكر در زمان مناسب كشت شود، متوسط درجه حرارت مورد نياز خود را در زمان كوتاهترى دريافت كرده و مراحل رشدى را در مدت زمان مناسب و با درجه حرارت مطلوبترى سيرى مىنمايد و در مقابل

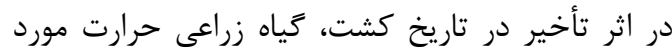




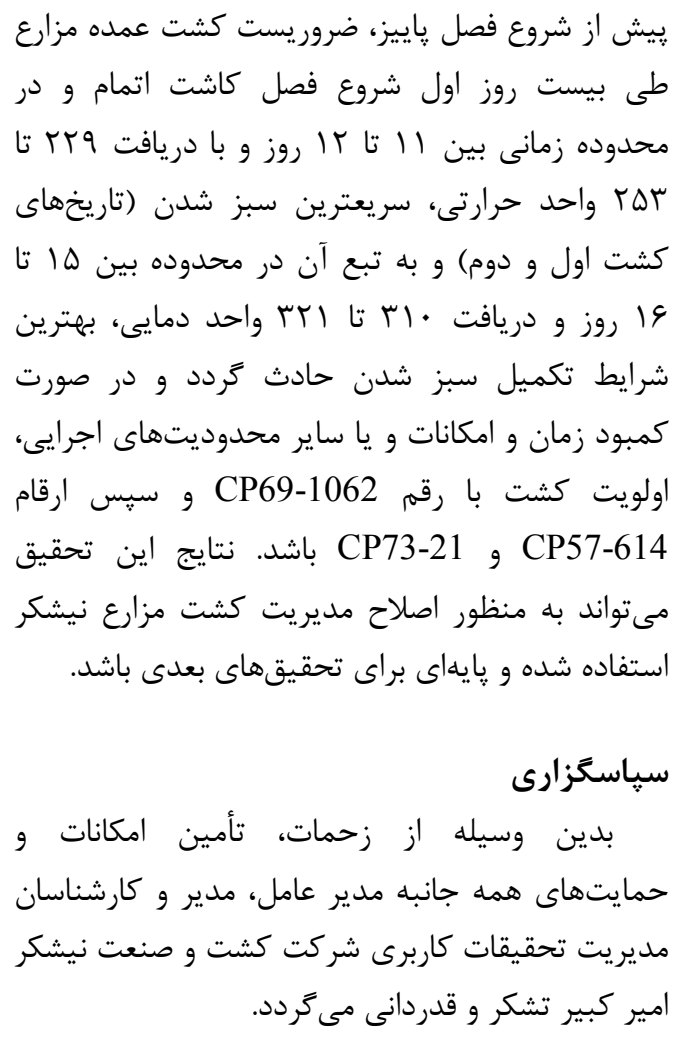

$$
\begin{aligned}
& \text { اوليه در رشد و تجمع ماده خشك نيشكر را به علت }
\end{aligned}
$$

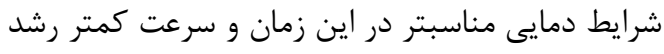

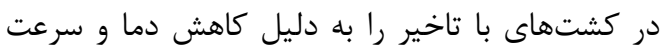

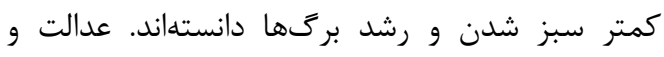

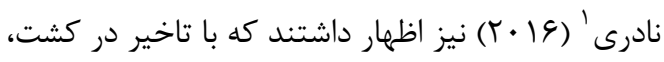

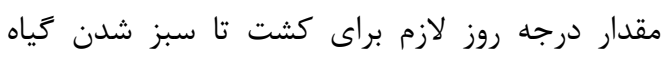

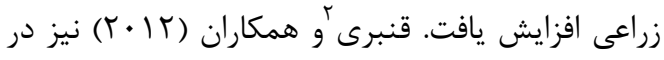

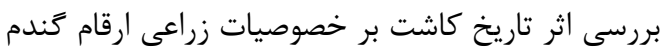

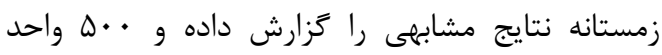

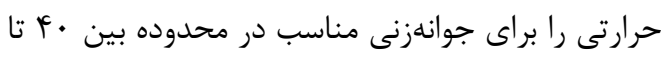

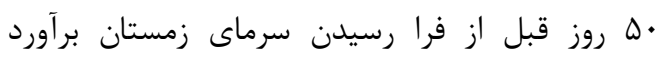

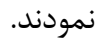

$$
\begin{aligned}
& \text { نتيجه } \\
& \text { در شرايط كشت و صنعتهاى نيش نيشكرى جنوب }
\end{aligned}
$$

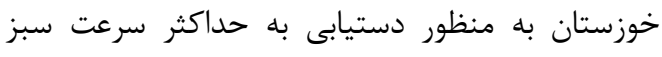

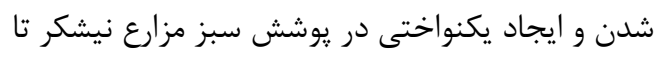

منابع

Ahmed, A.Z., Sogheir, K.S. and Shalby, N.M. 2007. Performance of some sugarcane verities at different planting dates. African Crop Science, 8: 161-172.

Allison, J.C.S., Pammenter, N.W. and Haslam, R.J. 2007. Why does Saccharum officinarum hybrid grow slowly? South African Journal of Botany, 73: 546-551. https://doi.org/10.1016/j.sajb.2007.04.065

Anapalli, S.S., Nielsen, L.M., Vigil, M.F. and Ahuja, L.R. 2005. Simulating planting date effect on corn production using RZWQM and CERES-Maize models. Agronomy Journal, 97(1): 58-71. https://doi.org/10.2134/agronj2005.0058

Bani Abbasi, N., Azizi, H., Mehregan, M., Malzoumati, M., Kazemi, K., Darivandpour, A. and Shomeyli, M. 2013. Sugarcane Production in Iran, Agronomic Guidelines for Sugarcane Production. Rosvaxheh Publication. 273p. [In Persian].

Bell, M.J. and Garside, A.L. 2005. Shoot and stalk dynamics and the yield on sugarcane crops in tropical and subtropical Queensland, Australia. Journal of Field Crop Research, 92: 231-248. https://doi.org/10.1016/j.fcr.2005.01.032

Brown, D.M. and Bootsma, A. 1993. Crop heat units for corn and other warm season crops in ontario. Ontario Ministry of agriculture and food factsheet Agdex 111/31. ISSN No. 0225-7882. Ontaro Ministry of Agriculture.

Castro Nava, S. and Huerta, A.J. 2016. Leaf growth and canopy development of three sugarcane genotypes under high temperature rainfed conditions in northeastern Mexico. International Journal of Agronomy, 2016, 1-7. https://doi.org/10.1155/2016/2561026

\footnotetext{
${ }^{1}$ Edalat and Naderi

${ }^{2}$ Ghanbari
} 
Edalat, M. and Naderi, R. 2016. Effect of planting date on seed yield and phonology of hybrid maize. Journal of Crop Production and Processing, 19: 49-66. [In Persian with English Summary]. https://doi.org/10.18869/acadpub.jcpp.6.19.49

Forouzi, M., Ehteshami, S.M.R., Esfehani, M. and Rabiee, M. 2015. Effect of seed size on emergence rate, germination indices, seedling growth and yield of four bread wheat cultivars (Triticum aestivum L.). Journal of Cereal Research, 5: 67-82. [In Persian with English Summary].

Ghanbari, A., Roshani, H. and Tavasoli, A. 2012. Effect of planting date on seed yield of winter wheat cultivars. Journal of Crop Eco-physiology, 6(2): 127-144. [In Persian with English Summary].

Inman Bamber, N.G. 1994a. Temperature and seasonal effects on canopy development and light interception of sugarcane. Journal of Field Crop Research. 36(1): 41-51. https://doi.org/10.1016/0378-4290(94)90051-5

Inman Bamber, N.G. 1994b. Effect of age and season on yield components. In Proceedings of the South African Sugar Technologists Association, 68: 23-27.

Khalili, N., Soltani. A., Zeinali, E. and Ghaderi far, F. 2013. Evaluation of nonlinear regression models to quantify barley germination rate response to temperature and water potential. Journal of Crop Production, 7(4): 23-40. [In Persian with English Summary].

Laure, J.G., Carter, P.R., Wood, T.M., Daniel, G.D. Robert, W. Rand, E. and Miynarek, M.J. 1999. Corn hybrid response to planting date in the northern Corn Belt. Agronomy Journal, 91(5): 834-839. https://doi.org/10.2134/agronj1999.915834x

Liu, D.L., Kingston, G. and Bull, T.A. 1998. A new technique for determining the thermal parameters of phenological development in sugarcane, including suboptimum and supraoptimum temperature regimes. Journal of Agriculture and Forest Meteorology, 90(1-2): 119139. https://doi.org/10.1016/S0168-1923(97)00087-7

Meier, U., Feller, C. Van den Boom, T. and Bleiholder, H. 2001. Growth stages of mono-and dicotyledonous plants, $\mathrm{BBCH}$ Monograph. Federal Biological Research Centre for Agriculture and Forestry. 2nd edition.

Munsif, F., Zahid, M. Arif, M. Ali, K. and Ahmad, I. 2018. Influence of planting date on yield and quality of sugarcane under the agro-climatic condition of mordan. Sarhad Journal of Agriculture, 34(3): 649-655. https://doi.org/10.17582/journal.sja/2018/34.3.649.655

Robertson, M.J. and Doualdson, R.A. 1998. Changes in the components of cane and sucrose yield in response to drying-off sugarcane before harvest. Field Crop Research, 5: 201-208. https://doi.org/10.1016/S0378-4290(97)00065-8

Sandhu, I.S., Sharma, A.R. and Sur, H.S. 1999. Yield performance and heat unit requirement of wheat (Triticum aestivum L.) varieties as affected by sowing dates under rainfed condition. Indian Journal of Agricultural Science, 69: 175-179.

Sela, G. 2017. Timing and frequency of fertilizer application. Available in: http://www.smartfertilizer.com/. (Accessed may 2017).

Sinclair, T.R., Gilbert, R.A., Perdomo, R.E., Shine, J.M., Powell, J.G. and Montes, G. 2004. Sugarcane leaf area development under field conditions in Florida, USA. Journal of Field Crop Research, 88: 171-178. https://doi.org/10.1016/j.fcr.2003.12.005

Smit, M.A. 2010. Characterising the factors that affect germination and emergence in sugarcane. In Proceedings of the Annual Congress-South African Sugar Technologists' Association. South African Sugar Technologists' Association, 83: 230-234

Vasantha, S., Gupta, C. and Shekinah, D.E. 2014. Physiological studies on tiller production and its senescence in sugarcane response comparison between plant and ratoon crops. Indian Journal of Agriculture Sciences, 84(1): 24-27. 


\title{
Research Article \\ Study of Bud Emergence Characteristics and Seedling Growth of Sugarcane (Saccharum officinarum) Cultivars on Different Planting Dates
}

\author{
Mohammad Amin Makvandi ${ }^{1}$, Mousa Meskarbashee ${ }^{2, ~}$, Payman Hassibi ${ }^{3}$, Hasan Hamdi ${ }^{4}$
}

Extended Abstract

Introduction: Management of agricultural operations in sugarcane fields should be informed by the accurate knowledge of sugarcane growth stages and phenology and is to be reviewed based on variety differences. Given the importance of emergence stage on the establishment of seedling and final quality and quantity of sugarcane yield and given the absence of respective information, a study was conducted to investigate the effect of different planting dates on the phenological characteristics of the seedling stage of sugarcane cultivars in the south of Khuzestan Province during 2016-17 and 2017-18.

Materials and Methods: The experiment was carried out as a randomized complete block design with three replications. In terms of growth period length, Very premature, Premature, and Semi mature cultivars included CP73-21, CP57-614 and CP69-1062. Planting dates were Aug. 11 ${ }^{\text {th }}$, Aug. $23^{\text {rd }}$, Sep. $1^{\text {st }}$ and Sep $11^{\text {th }}$. Planting operation was conducted manually and with $1 / 3$ overlap of grafts. In order to prevent the negative effects brought about by the dispersion and non-uniformity of the experimental field and the special conditions of sugarcane cultivation, each cultivar was cultivated in a separate field and after sampling and the study of different traits, the statistical analysis of each cultivar was performed separately.

Results: The results showed that sugarcane seedling was not affected by annual conditions and the interaction effect of annual conditions and planting dates. The significant differences of planting dates were observed at the beginning of emergence, its completion and rate of emergence and the number of leaves produced and their area. The fastest rate of the beginning and the completion of emergence was obtained in CP73-21, and on different planting dates, it was more permanent than other cultivars studied, while CP691062 had the slowest and more behavioral diversity of emergence on different planting dates. The cultivar CP73-21 did not produce good results in terms of leaf area, but the CP69-1062 cultivar was able to produce the highest level of leaf area due to the extra number of leaves and the mean value of a single leaf area. In addition, the best results were obtained in all characteristics in August, followed by September.

Conclusions: Based on the results, in order to achieve the best emergence of sugarcane buds, it is necessary to complete the cultivation of most of the fields within the first twenty days of the beginning of the planting season and priority should be given to cultivar CP69-1062 and then cultivars CP57-614 and CP7321 . Due to the differences between sugarcane cultivars, utilizing seedling stage growth data can lead to more scientific management of the crops in terms of the characteristics of each cultivar, which eventually leads to desirable yields.

\section{Keywords: Emergence beginning, Emergence completion, Emergence rate, Leaf area}

\section{Highlights:}

1-Estimation and comparison of emergence characteristics of commercial cultivars of sugarcane under farm conditions.

2-Study of the effect of planting dates on leaf development characteristics of important commercial sugarcane cultivars in early growth stages.

3-Determination of the best planting date for sugarcane cultivars based on the seedling stage characteristics.

I P.h.D Student of Crop Physiology, Department of Agronomy and Plant Breeding, Faculty of Agriculture, Shahid Chamran University of Ahvaz, Ahvaz, Iran

${ }^{2}$ Associate Professor, Department of Agronomy and Plant Breeding, Faculty of Agriculture, Shahid Chamran University of Ahvaz, Ahvaz, Iran

${ }^{3}$ Professor, Department of Agronomy and Plant Breeding, Faculty of Agriculture, Shahid Chamran University of Ahvaz, Ahvaz, Iran

4 Researcher of Institute of sugarcane research and instruction, Ahvaz, Iran

*Corresponding author E-mail: mmeskarbashee@scu.ac.ir http://dorl.net/dor/20.1001.1.23831251.1398.6.2.8.0

http://dx.doi.org/10.29252/yujs.6.2.81

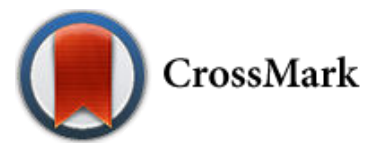

